\title{
Interlinkages among Exchange Rate, Interest Rate, Consumer Price Index, and Output Volatilities
}

\author{
Rashid Rauf and Abdul Rashid ${ }^{1}$
}

\begin{abstract}
In this paper, we investigated the interlinkages between real exchange rate volatility (VRER), consumer price volatility (VCPI), industrial output volatility (VLMI), and interest rate volatility (VINT) using monthly data covering the period January 1988-December 2017. We applied a multivariate model of Granger causality and found bidirectional causality between VRER and VLMI. Similarly, we found bidirectional causality between VRER and VINT. Whereas, unidirectional Granger causality running from VCPI to VRER, VLMI to VCPI, and VINT to VLMI. The results of variance decomposition show that the VRER error forecast is mainly attributed to its own shock. However, after 18 months it reaches to $94.6 \%$ while the remaining 5.4\% error forecast is explained by VLMI, VCPI, and VINT shocks. In a similar manner, at a time horizon of 1 month, 99.5\% of the VINT error forecast is associated with its own shock but after 18 months it declines to 89.6\%. As expected, the VLMI error forecast is mainly attributed to its own shock and it declines to $97.2 \%$ after 18 months. Contrary to this, at a time horizon of 1 month, $97.6 \%$ of the VCPI error forecast is attributed to its own shock, whereas after 18 months, it rises to $98.8 \%$, remaining $1.2 \%$ is due to VRER, VLMI, and VINT shocks. The impact of VRER on VRER, VCPI, and VINT is positive but it fades away with a short passage of time. Likewise, the effect of VCPI on VRER and VCPI is positive and convergent. In contrast, the response of VRER and VINT is positive and persistent. The response of all the macroeconomic series, except VLMI to VINT, is convergent.
\end{abstract}

Keywords: Real Exchange Rate Volatility, Consumer Price Volatility, Output Volatility, Interest Rate Volatility, Granger Causality, Variance Decomposition, Impulse Response, Structural Break

JEL classification: C22, D81, E31

\section{Introduction}

Researchers had given attention to the macroeconomic volatility as one of the main factors responsible for the 2007-09 financial crisis. Stock and Watson

\footnotetext{
${ }^{1}$ The authors are Lecturer and Associate Professor at International Institute of Islamic Economics (IIIE), International Islamic University, Islamabad.

Corresponding author's Email: rashid.rauf@iiu.edu.pk
} 
(2012) are also of the view that "the main contributions to the decline in output and employment during the (2007-2009) recession are estimated to come from financial and uncertainty shocks". Knight (1921) defined "volatility as peoples' inability to forecast the likelihood of events happening". Volatility is the exposure to the chance of loss, a hazard, a danger, or the probability of loss. Volatility remains in the mind of all individuals, consumers, producers, and policymakers due to the uncertain future. Volatility is cyclical. It has been observed higher during recessions and lower during the boom (Bloom, 2014; Veirman and Levin, 2018). Furthermore, Loayza et al. (2007) are of the view that volatility remains higher in developing countries (Barrot et al., 2018) as compared to developed countries. They found that not only small developing economies like Dominican Republic and Tong but also large countries like Argentina and China and rapidly industrialized countries, for example, Indonesia and Peru are facing higher macroeconomic volatility over the past forty years.

The link between volatility and economic growth is ambiguous (Imbs, 2007). Pham (2018) presented a mixed relationship between volatility and growth. In a volatile environment, investors may feel reluctant to invest, which results in lessor economic growth. Ramey and Ramey (1995) presented empirical evidence that countries with volatile GDP tend to grow at a much lower rate than the countries with stable GDP. Theoretically, higher volatility has an adverse impact, initially on employment and investment in a country, and ultimately, it results in a decline in the economic growth of the country. Loayza et al. (2007) argued that empirical connection between macro-level volatility and underdevelopment cannot be denied and it is the main developmental hurdle. The adverse effects of volatility on economic growth were initially explored by Ramey and Ramey (2005). Later on, several other researchers also reported a negative relationship between volatility and economic growth (see, for instance, Acemoglu, 2003; Loayza and Hnathovska, 2004; Barguellil et al., 2018). Volatility in industrial output has significant adverse effects on an economy (Loayza et al., 2007). Volatility plays an important role in many financial applications like the value of market risk, pricing of financial derivatives, risk management, and portfolio management (Ladokhin, 2009). Therefore, it is very important for us to know not only the historical trends in the volatility of different macroeconomic series (exchange rates, consumer prices, interest rates, and industrial output) but also the interlinkages (in Granger sense) between these macroeconomic volatilities. Empirical knowledge on the direction of causation between these volatility series helps us to forecast variations in the underlying macroeconomic indicators based on the information about the other one. Further, empirical evidence on the interlinkages between volatility of different 
macroeconomic indicators would be of great significance to policymakers, business firms, and academicians for understanding the dynamic and interconnected macroeconomic mechanism.

In the recent past, researchers indeed have focused on macroeconomic volatility (see, for instance, Ramey and Ramey, 2005). Yet only a few empirical studies analyzed the interlinkages between various macro-level volatilities (Morana, 2009; Jabeen and Khan, 2014). The empirical literature on the interlinkages between VRER, VCPI, VLMI, and VINT remained silent.

Although we do not have any empirical evidence on how different types of macroeconomic volatilities are interlinked with each other, there is a huge literature on the causation between macroeconomic indicators. For instance, Ajayi et al. (1998) found unidirectional causality between stock prices and ER for developed economies, whereas, in the case of emerging economies, they reported mixed results. Many researchers (see, for instance, Muhammad and Rashid, 2002; Jawaid and Haq, 2012) found bidirectional causality between stock prices and ER and unidirectional causality between interest rate and stock prices. Nishat et al. (2005) found that macroeconomic variables (namely interest rate, industrial production index, CPI and money supply) caused stock price. Rashid (2008) found bidirectional causality between different macroeconomic variables (namely, ER, CPI, output, and interest rate) and stock prices. He also reported bidirectional causality between industrial production index and stock prices. Tursoy (2017) found bidirectional causality between stock prices and ER, in the short run, only ER causes stock prices. Dlamini and Skosana (2017) reported that the interest rate causes CPI.

Numerous researches found unidirectional causality between CPI and ER running from CPI to ER (see, for instance, Khin et al., 2014; Ali et al., 2015; Rehman and Aftab, 2015). Particularly, Khin et al. (2014) found bidirectional causality between ER and money supply. Zhu (2012) used monthly data and found unidirectional causality from ER to CPI. Abdalla and Murinde (1997) found that ER causes CPI for India, Pakistan, South Korea, and the Philippines and their results are in line with the traditional approach. Berument and Pasaogullari (2003) analyzed the Granger causality between ER and output they reported no significant causal relationship between the variables. Kholdy and Sohrabian (1990) reported the causal relationship running from wholesale prices to ER.

Jabeen and Khan (2014) documented that VRER is influenced by several macroeconomic volatilities. Similarly, Morana (2009) argued that there is a linkage between ER and macroeconomic volatility, namely VLMI and VCPI. Similarly, 
Rashid (2008) found that causation runs from macro-level variables to stock prices. However, stock market crises can be avoided by controlling macroeconomic volatilities, mainly VRER and VINT. From the extant literature, we can conclude that there is no single study examining the interlinkages between various macroeconomic volatilities, particularly VRER, VCPI, VLMI, and VINT.

For both policy and business point of view, it is very useful to know whether one type of macroeconomic volatility, say VRER, amplifies or minifies another type of macroeconomic volatility, for instance, VCPI. To fulfill the existing gap in the empirical literature, in this paper, we intend to examine the interlinkages (in Granger sense) between several different types of macroeconomic volatilities. Specifically, we empirically examine the presence of Granger causality between VRER, VCPI, VLMI, and VINT. For this purpose, we proceed with our empirical investigation as follows. First, we apply the unit root test to know the order of integration of the underlying macroeconomic series. Next, we estimate the ARCH/GARCH model for each macroeconomic series to obtain the conditional variance series, which we use as a proxy for volatility.

To achieve the objective of the paper, study apply the Granger causality test in a multivariate framework. After knowing the statistical significance and direction of Granger causality, we apply variance decomposition and impulse response function (IRF) to know how shocks to one type of macroeconomic volatility transmit to another type of macroeconomic volatility. Application of IRF also enables us to know whether the response of the underlying macroeconomic volatility to one standard deviation shock to another type of macroeconomic volatility is persistent or die out after some time. The findings of the study are indeed very helpful for policymakers. The study found bidirectional Granger causality between VRER and VLMI. Similarly, researcher found bidirectional causality between VRER and VINT.

The paper is structured as follows. Section one covers the introduction. Section two describes the methodology. The third section presents descriptive statistics, unit root test results, estimation of $(\mathrm{G}) \mathrm{ARCH}$ models, graphs of volatility series, correlations between volatility series, Granger causality test results, variance decomposition, and impulse response. Section four is dedicated to draw some conclusions and policy recommendations.

\section{Methodology}

We utilized monthly time series data namely ER, CPI, and IR extracted from IMF's International Financial Statistics (IFS). Further, LSM series is taken 
from the State Bank of Pakistan. ER represents the real effective exchange rate based on CPI as suggested by Sarantis (1999). Similarly, CPI represents the consumer price index, LSM represents large scale manufacturing index based on 2005-06, and the money market rate as a proxy for IR. Moreover, LCPI and LLSM represent the logarithm of CPI and LSM series respectively. The data span is thirty years, from January 1988 to December 2017. In this paper, we utilized the Augmented Dickey-Fuller (hereafter, ADF) and Kwiatkowski-Phillips-SchmidtShin (hereafter, KPSS) for testing the presence of unit root. In order to measure the volatility of macroeconomic series, we applied ARCH/GARCH models.

\subsection{Measuring Volatility}

To measure the macroeconomic volatility, we follow the standard ARCH and GARCH techniques developed by Engle (1982) and Bollerslev (1986), respectively. Since their introductions, these models are the most widely used techniques to measure volatility. Ordinary least square is based on the assumption of homoscedasticity. In the absence of homoscedasticity, ARCH/GARCH technique can be used to handle the problem of heteroscedasticity.

We gauge the volatility by using the following model for the underlying macroeconomic variables.

$$
\begin{aligned}
& \Delta M V_{t}=\omega+\beta(\mathrm{L}) \Delta M V_{t}+\delta(\mathrm{L}) \varepsilon_{t}+\varepsilon_{t} \\
& \sigma_{t}^{2}=\alpha+\gamma(\mathrm{L}) \varepsilon_{t}^{2}+\lambda(\mathrm{L}) \sigma_{t}^{2}
\end{aligned}
$$

Where (MV) represents macroeconomic variables, $(\omega)$ and $(\alpha)$ are the constant terms, $(\beta)$ and $(\delta)$ are autoregressive $(\mathrm{AR})$ and moving average (MA) parameters, respectively and $(\mathrm{L})$ is the lag polynomial operator. The estimated conditional variance, $\left(\sigma_{t}^{2}\right)$, is the one-period ahead forecast variance based on prior information and $\left(\varepsilon_{t}\right)$ is the error term. We used ARCH-LM to test the presence of ARCH effects. We examine the interlinkages between the four-volatility series viz VRER, VCPI, VLMI, and VINT in a multivariate Granger causality framework. Specifically, we estimate the following equations.

$V R E R_{t}=\sum_{i=1}^{p} \alpha_{i} V R E R_{t-i}+\sum_{i=1}^{p} b_{i} V C P I_{t-i}+\sum_{i=1}^{p} c_{i} V L M I_{t-i}+$ $\sum_{i=1}^{p} \delta_{i} V I N T_{t-i}+\varepsilon_{t}$

$V C P I_{t}=\sum_{i=1}^{p} a_{i} V R E R_{t-i}+\sum_{i=1}^{p} b_{i} V C P I_{t-i}+\sum_{i=1}^{p} c_{i} V L M I_{t-i}+$ $\sum_{i=1}^{p} \delta_{i} V I N T_{t-i}+\mu_{t}$

$V L M I_{t}=\sum_{i=1}^{p} a_{i} V R E R_{t-i}+\sum_{i=1}^{p} b_{i} V C P I_{t-i}+\sum_{i=1}^{p} c_{i} V L M I_{t-i}+$ $\sum_{i=1}^{p} \delta_{i} \operatorname{VINT}_{t-i}+\eta_{t}$ 
$V{ }^{\prime N T} T_{t}=\sum_{i=1}^{p} a_{i} V R E R_{t-i}+\sum_{i=1}^{p} b_{i} V C P I_{t-i}+\sum_{i=1}^{p} c_{i} V L M I_{t-i}+$ $\sum_{i=1}^{p} \delta_{i} V I N T_{t-i}+\tau_{t}$

Where all the variables are regressed on their own lags and lags of the other explanatory variables. Further, we assumed that the error terms are independent from each other. For the analysis of forecast variance decomposition, we utilized forecast horizon of $1,6,12$, and 18 months.

\section{Results}

This section by presenting descriptive statistics of macroeconomic variables namely, ER, LCPI, LLSM, and IR. In particular, Table 1 depicts the mean, median, maximum, minimum, standard deviation, coefficient of variation (CV), skewness, and kurtosis.

Table 1: Descriptive Statistics of Macroeconomic Variables

\begin{tabular}{lcccc}
\hline & ER & LCPI & LLSM & IR \\
\hline Mean & 108.259 & 3.938 & 4.307 & 8.577 \\
Median & 107.327 & 3.838 & 4.264 & 8.758 \\
Maximum & 141.543 & 5.074 & 5.157 & 20.030 \\
Minimum & 89.472 & 2.657 & 3.405 & 0.740 \\
Std. Dev. & 11.499 & 0.709 & 0.450 & 3.362 \\
Skewness & 0.467 & 0.034 & -0.118 & -0.396 \\
Kurtosis & 2.413 & 1.905 & 1.615 & 1.742 \\
CV & 0.106 & 0.180 & 0.104 & 0.392 \\
\hline Jarque-Bera & 18.266 & 18.029 & 29.577 & 1.124 \\
Probability & 0.0001 & 0.0001 & 0.0000 & 0.569 \\
\hline
\end{tabular}

The table shows that the CV of the IR series is 0.392, which is much larger, as compared to ER, LCPI, and LLSM. In developing countries, like Pakistan, the IR has been remained volatile in recent years. The ER and LCPI series are positively skewed, whereas, LLSM and IR series are negatively skewed.

The unit root of all the series of macroeconomic variables is checked. For this purpose, we used the ADF test. For unit root tests, Elder and Kemedy (2001) suggested that if the graph of series shows continuous growth, then one should apply the ADF test with a constant, if the graph seems to be closer to a straight line, then one should also add trend into the specification. This was first analyzed the graphs of all the series. The graph of the LCPI series shows continuous growth. Therefore, for the application of the ADF test, researcher must add a constant. The graph of LLSM also shows growth over time. Hence, we will apply the ADF test by including an intercept term in the specification of the ADF equation. 
Graphs of ER and IR series depict that there is no increasing or decreasing trend in these series. Therefore, we can apply the ADF test at level without including a constant and linear trend into the equation. However, to get a clearer picture, we want to standardize our unit root tests. Therefore, we applied the ADF test at level with a constant as well as a constant and a linear trend, and at first differences, we applied the ADF test with only a constant. The results of the ADF test are given in Table 2.

Table 2: Unit Root Test (Results)

\begin{tabular}{lcccccc}
\hline & \multirow{2}{*}{$\begin{array}{l}\text { ADF- Stats (at level) } \\
\text { with Constant }\end{array}$} & \multicolumn{2}{l}{$\begin{array}{l}\text { ADF- Stats (At level) } \\
\text { with Constant and } \\
\text { Linear Trend }\end{array}$} & $\begin{array}{l}\text { ADF- Stats (At First } \\
\text { Difference) with } \\
\text { Constant }\end{array}$ \\
\hline Variables & t-stat. & Probability & t-stat. & Probability & t-stat. & Probability \\
\hline LCPI & -0.954 & 0.770 & -2.195 & 0.491 & -2.899 & 0.046 \\
LLSM & -0.628 & 0.861 & -2.219 & 0.476 & -3.137 & 0.025 \\
ER & -2.182 & 0.213 & -1.654 & 0.769 & -8.892 & 0.000 \\
IR & -1.803 & 0.379 & -1.757 & 0.723 & -10.224 & 0.000 \\
\hline
\end{tabular}

The ADF test shows that we are unable to reject the presence of unit root in all four cases. This finding holds regardless we include only a constant or a constant and a linear trend in the ADF equation. The ADF test suggests that all the four variables are stationary at their first differences, although at different levels of significance. At first difference, both LCPI and LLSM are stationary at the 5\% level of significance, whereas, the first difference of ER and IR appear stationary at the $1 \%$ level of significance. Before applying the ARCH/GARCH researcher use ARCH-LM to test the presence of ARCH effects. The results of the LM test and Qstats suggest that all the four series have an ARCH effect ${ }^{2}$.

Table 3: ARCH/GARCH Estimates for Macroeconomic Risk

\begin{tabular}{lcccc}
\hline \multicolumn{1}{c}{ Regressors } & $\Delta \mathbf{L C P I}$ & $\Delta \mathbf{L L S M}$ & $\Delta \mathbf{E R}$ & $\Delta \mathbf{I R}$ \\
\hline Constant & $0.005 * * *$ & 0.003 & -0.042 & 0.010 \\
& $(0.0004)$ & $(0.004)$ & $(0.114)$ & $(0.032)$ \\
AR(1) & $-0.541^{* * *}$ & 0.329 & -0.176 & $0.245^{* * *}$ \\
& $(0.130)$ & $(1.389)$ & $(0.143)$ & $(0.061)$ \\
MA(1) & $0.749 * * *$ & -0.293 & 0.522 & $-0.804 * * *$ \\
& $(0.110)$ & $(1.391)$ & $(0.124)$ & $(0.042)$ \\
\hline
\end{tabular}

\footnotetext{
${ }^{2}$ The LM test and Q-stats results for macroeconomic series are not reported here to economize pace. However, the results are available from the authors on request.
} 


\begin{tabular}{lcccc}
\hline Constant & $0.000003^{*}$ & 0.00006 & $1.161^{*}$ & $4.119 * * *$ \\
& $(0.00001)$ & $(0.00005)$ & $(0.615)$ & $(0.364)$ \\
ARCH(1) & $0.072 * *$ & $0.021^{* *}$ & $0.172^{* * *}$ & $0.333^{* * *}$ \\
& $(0.029)$ & $(0.010)$ & $(0.063)$ & $(0.097)$ \\
GARCH(1) & $0.865^{* * *}$ & $0.968^{* * *}$ & $0.431^{*}$ & - \\
& $(0.053)$ & $(0.014)$ & $(0.240)$ & \\
\hline \multicolumn{5}{c}{ Diagnostic Tests for Remaining GARCH Effects } \\
\hline Oog-likelihood & 1259.252 & 360.027 & -689.971 & -760.385 \\
LM-test & 358 & 358 & 358 & 358 \\
P Value & 0.021 & 0.008 & 0.037 & 0.523 \\
Q-stat & 0.883 & 0.926 & 0.847 & 0.470 \\
P Value & 0.022 & 0.009 & 0.037 & 0.531 \\
\hline
\end{tabular}

Note: $* * *, * *, *$ represents significant at the $1 \%, 5 \%$, and $10 \%$ level, respectively

After confirming the presence of $\mathrm{ARCH}$ effect in all the macroeconomic series, we estimate (G)ARCH models to obtain the GARCH variance series. The graphs of these volatility series are presented in Figures 1 to 4.

Figure 1: GARCH Variance Series of CPI

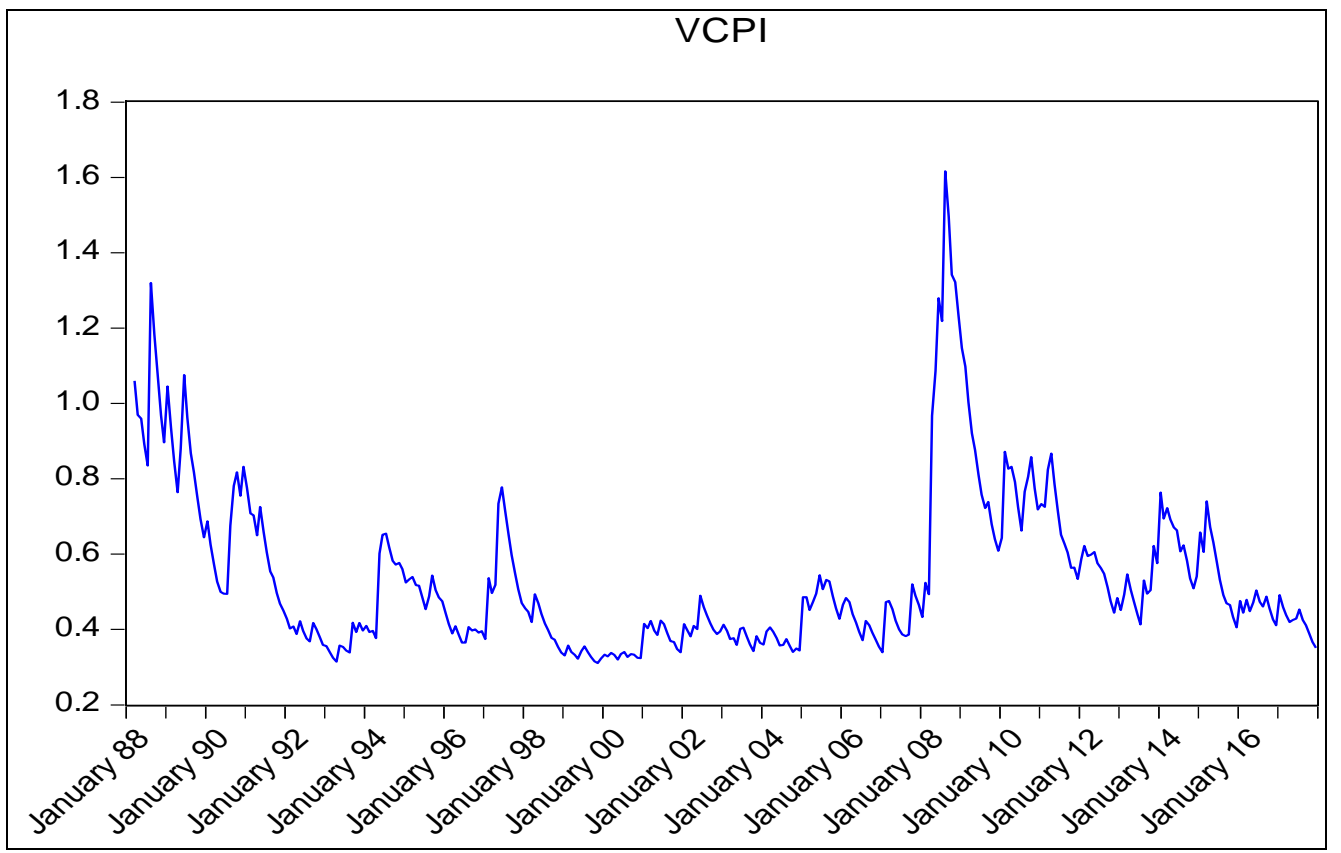

VCPI GARCH variance series shows a spike during 2008-09, showing the higher volatility during the crisis period. 
Figure 2: GARCH Variance Series of Large-Scale Manufacturing Index

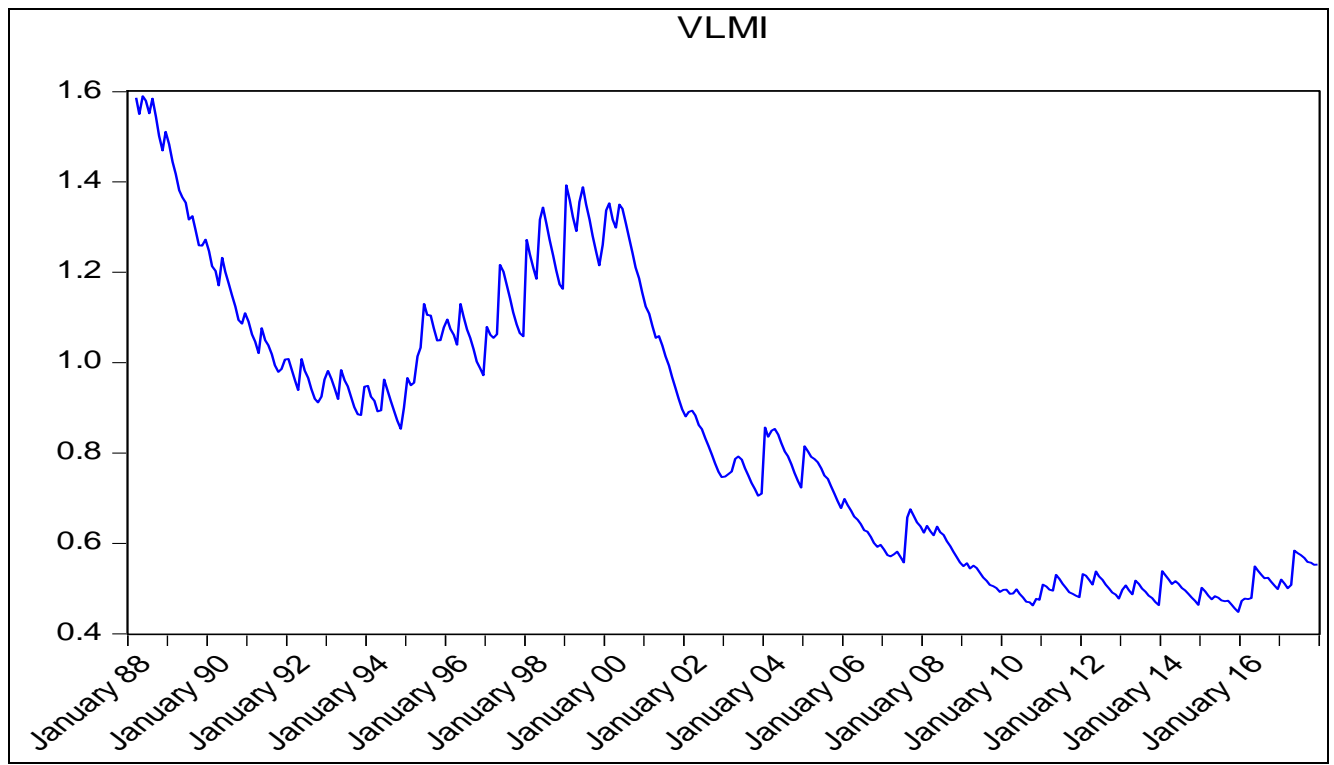

Figure 3: GARCH Variance Series of Real Exchange Rate

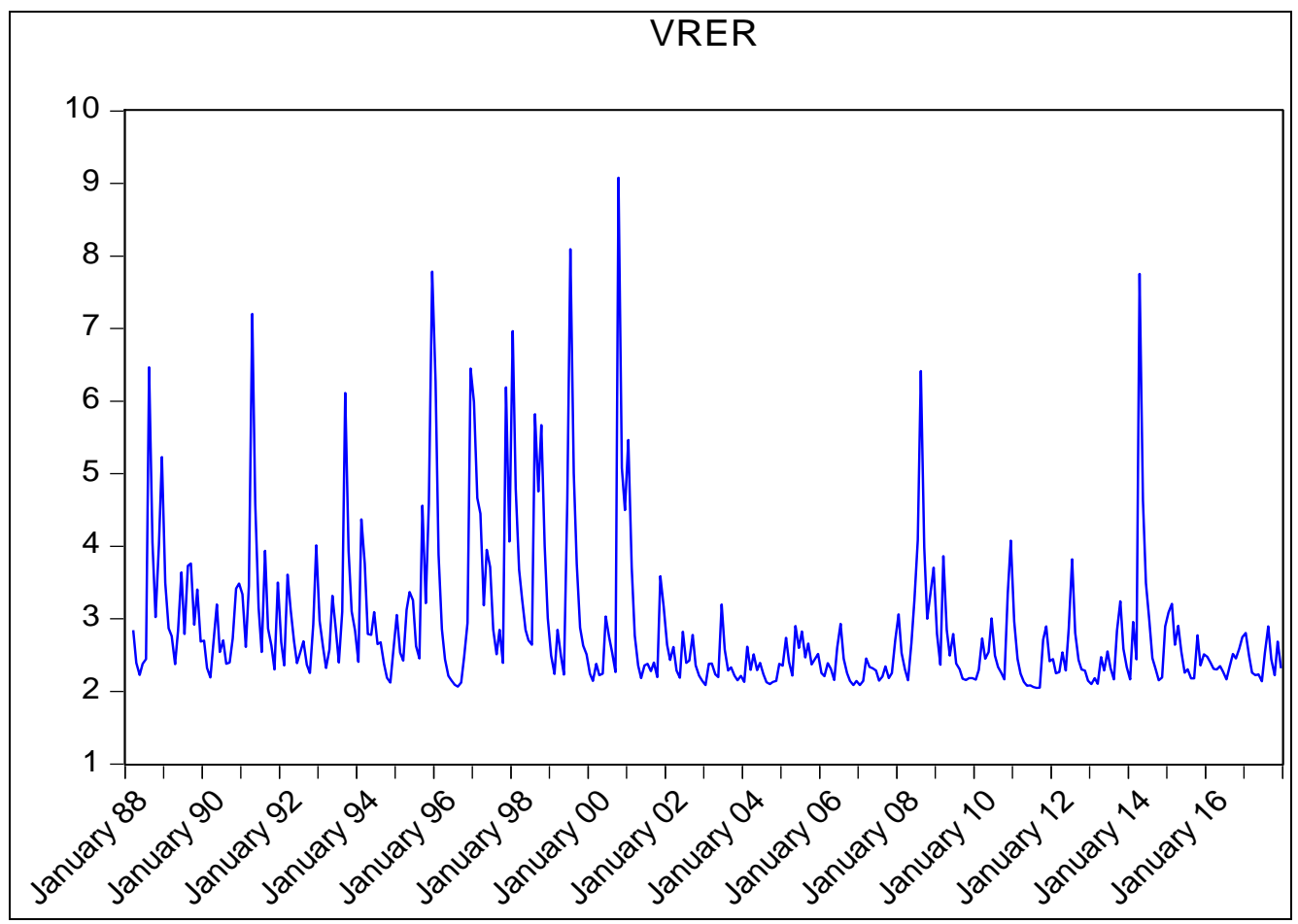


Figure 4: GARCH Variance Series of Interest Rate

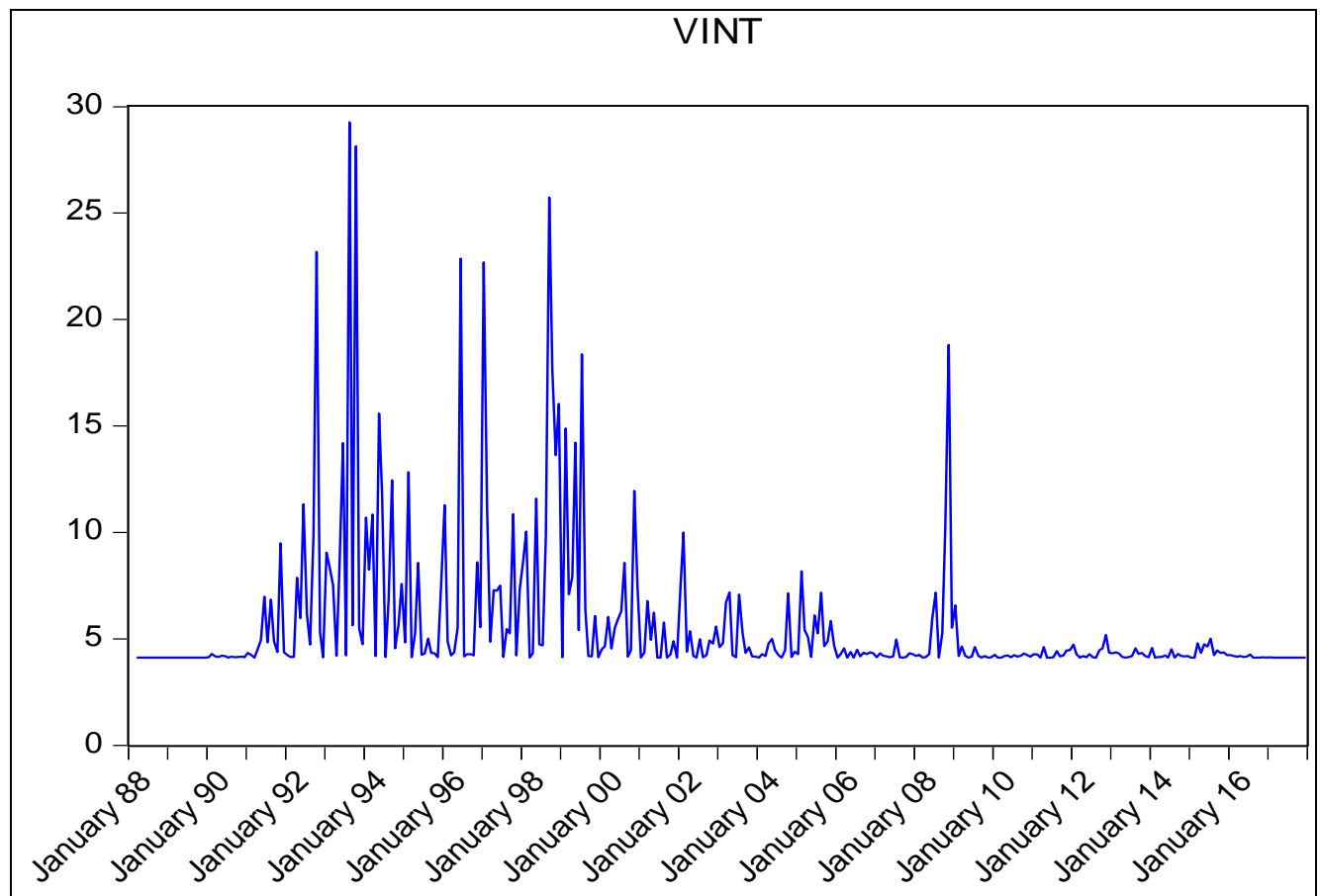

However, the VLMI GARCH variance series showed a deviation during and after the third quarter of 2000. Such a reduction in variance series may initially be associated with the change in the political setup during 1999 and later with changed economic-political scenario after the 9/11.

The GARCH volatility series of VRER and VINT remained much more volatile till the $9 / 11$ event but the volatility of these series diminished after the 9/11 event.

The underlying macroeconomic volatility series are stationary at their level $^{3}$. To obtain the preliminary evidence on the interlinkages between the four macroeconomic volatilities we estimate correlation and presented in Table 4.VCPI series is negatively correlated with both VLMI and VINT, while, VCPI and VRER are positively related. VLMI and VRER are also positively correlated with each other, but the magnitude of correlation is relatively strong. Furthermore, VLMI and

\footnotetext{
${ }^{3}$ The results of ADF and KPSS unit root tests are not reported here to conserve space. However, the results are available from the authors on request.
} 
VINT are also weakly positively correlated, on the other hand, VINT and VRER series are weakly negatively correlated.

Table 4: Correlation among Volatility Series

\begin{tabular}{lccc}
\hline & VCPI & VLMI & VINT \\
\hline VLMI & -0.032477 & & \\
VINT & -0.020728 & 0.033148 & \\
VRER & 0.134227 & 0.326177 & -0.011282 \\
\hline
\end{tabular}

All the volatility series are stationary at their levels. Therefore, we moved towards the next step of multivariate Granger causality. The results of the multivariate Granger causality analysis are presented in Table 5.

Table 5: Granger Causality Test Results

\begin{tabular}{lcc}
\hline \multicolumn{3}{c}{ Dependent Variable: VRER } \\
\hline Excluded & Chi-sq & Prob. \\
\hline VCPI & 23.978 & 0.031 \\
VLMI & 42.136 & 0.000 \\
VINT & 24.478 & 0.027 \\
All & 88.124 & 0.000 \\
\hline \multicolumn{3}{c}{ Chi-sq } \\
\hline Excluded & 14.906 & Prob. \\
\hline VLMI & 25.969 & 0.313 \\
VINT & 5.482 & 0.017 \\
All & 44.737 & 0.963 \\
\hline & Dependent Variable: VCPI \\
\hline Excluded & 21.670 & 0.244 \\
\hline VRER & 10.155 & \\
VCPI & 38.656 & Prob. \\
VINT & 71.672 & 0.061 \\
All & Dependent Variable: VLMI & 0.681 \\
\hline & Chi-sq & 0.000 \\
\hline Excluded & 30.823 & 0.001 \\
\hline VRER & 11.972 & \\
VCPI & 13.194 & Prob. \\
VLMI & 58.155 & 0.004 \\
All & Dependent Variable: VINT \\
\hline
\end{tabular}

The results of the multivariate Granger causality test suggest that there is a significant bidirectional causality between VRER and VLMI. Similarly, we found 
bidirectional causality between VRER and VINT. Said differently the findings suggest that the VRER not only significantly Granger causes VLMI and VINT but also statistically significantly Granger caused by these two types of volatilities. This piece of evidence implies that the heightened exchange rate volatility significantly amplifies the volatilities of interest rates and industrial output. Likewise, any increase in VLMI and VINT has a significant feedback impact on VRER. The presence of bidirectional Granger causality in these three types of macroeconomic volatilities suggests that any uncertainty regarding exchange rates is harmful for industrial output and market interest rate in the economy. It also suggests that any uncertainty about VLMI and domestic interest rates significantly increases the uncertainty about the real exchange rate in the economy. From a policy point of view, these findings suggest that the authorities should minimize the unpredictable variations in industrial output and domestic interest rates in order to stabilize the real exchange rate in the economy. The results given in Table 5 also indicate all three macroeconomic volatilities namely VCPI, VLMI, and VINT jointly Granger cause VRER. The results also indicate that there is a unidirectional Granger causality running from VCPI to VRER. This particular finding implies that any uncertainty associated with domestic consumer prices significantly intensifies the volatility of the real exchange rate. This finding suggests that to bring the stabilization in the real exchange rate, it is necessary to curb the unnecessary and unwanted variations in consumer prices. We also find a unidirectional causality running from VLMI to VCPI, suggesting that any increase in unpredictable variations in VLMI will significantly lead to amplify variations in VCPI. However, the study did not find any significant evidence of the causation between VRER, VINT, and VCPI. This means that the volatility of RER and Interest rates does not significantly Granger cause the VCPI.

The results regarding which type of volatility Granger causing the VLMI show that all three macroeconomic volatilities, namely VRER, VCPI, and VINT jointly significantly Granger cause VLMI. Looking at the Granger causality test results and individual macroeconomic volatility series in the case of VLMI we observed that both VRER and VINT significantly Granger cause VLMI. These findings imply that any variation in the real exchange rate and the market interest rate significantly increases unpredictable variations in industrial outputs. The results of the model where VINT is a dependent variable indicates that all the three underlying volatilities simultaneously Granger cause VINT. However, the results on the individual Granger causality test suggest that only VRER significantly Granger causes VINT. This finding suggests that all three underlying volatilities, namely VRER, VCPI, and VLMI can jointly be used to predict VINT. 
Although the results presented in the study provide strong evidence on the interactions between the volatilities of exchange rates, interest rates, consumer prices, and industrial output, there is the possibility that these results are driven by any structural change in the data. To ensure that the results are robust to any structural break that occurred during the sample period, we presented another set of results where we take into account the possible effects of structural changes. Specifically, we considered two structural breaks in our dataset, nuclear test of 1998 and $9 / 11$ based on the previous literature. We suppose that these events may have considerable effects on the causal relationship between the underlying series. The results presented in the appendix are similar, in terms of both statistical significance and the direction of causality, to those obtained without considering the structural break during the examined period. Therefore, we concluded that our results of the presence of Granger causality between the underlying volatility series are robust to any structural break occurred during the sample period.

Table 6 presents forecast error decomposition of variances of the standard error for forecasting the variables due to shocks. At a time horizon of one month, $100 \%$ variations of VRER are attributed to its own shock. However, after six months, $96.5 \%$ of the error in the forecast of VRER is due to its own shock and the remaining $3.5 \%$ variation is explained by VCPI, VLMI, and VINT. In addition to that at a time horizon of 18 months, the said figure reduced to $94.6 \%$, representing $5.4 \%$ of the forecast error is due to VCPI, VLMI, and VINT. Contrarily, own shock forecast standard error of VCPI at a time horizon of one month is $97.6 \%$, whereas, at a time horizon of six months, it becomes $98.5 \%$. However, after 12 months, it becomes almost $98.8 \%$. Yet, at a time horizon of 18 months, it increases to $98.9 \%$. Initially, at a time horizon of one period, $97.9 \%$ of the forecast standard error of VLMI is due to its own shock. Nevertheless, at a time horizon of six months, it increases to $98.5 \%$, and after 12 months, it becomes $98.1 \%$. At a time horizon of 18 months, $2.8 \%$ of the forecast error of VLMI is due to the shocks of VRER, VCPI, and VINT and the remaining $97.2 \%$ is due to its own shock. We also observed a decline in own shock forecast standard error of VINT overtime. That is, at a time horizon of one month, about $99.5 \%$ of the error in the forecast of VINT is attributed to its own shock. However, after 18 months, the said forecast standard error diminishes to $89.6 \%$. In general, the variance decomposition results provide significant evidence on the interactions between the said macroeconomic volatilities.

The first column in Figure 5 shows the effect of an unexpected rise in VRER on all the four macroeconomic volatility series. The response of VRER, VCPI, and VINT to VRER is positive but it fades away with the passage of time. In contrast, 
the response of VLMI to VRER is positive and persistent over time. Similarly, the second column shows the effect of an unanticipated rise in VCPI on the underlying macroeconomic series. The response of both VRER and VCPI to VCPI is positive and convergent, overtime the response of VINT to VCPI is negative and convergent. Interestingly, the response of VLMI to VCPI is initially positive then it becomes zero and ultimately it becomes negative.

Table 6: Variance Decomposition of VAR (VRER, VCPI, VLMI, VINT)

\begin{tabular}{|c|c|c|c|c|c|}
\hline \multicolumn{6}{|c|}{ Variance Decomposition (Percentage points) of VRER } \\
\hline $\begin{array}{l}\text { Forecast } \\
\text { Horizon }\end{array}$ & $\begin{array}{c}\text { Forecast St. } \\
\text { Error }\end{array}$ & VRER & VCPI & VLMI & VINT \\
\hline 1 & 0.873 & 100 & 0.000 & 0.00 & 0.00 \\
\hline 6 & 1.009 & 96.5 & 0.418 & 0.52 & 2.56 \\
\hline 12 & 1.015 & 95.3 & 0.807 & 1.296 & 2.55 \\
\hline 18 & 1.018 & 94.6 & 0.922 & 1.909 & 2.54 \\
\hline \multicolumn{6}{|c|}{ Variance Decomposition (Percentage points) of VCPI } \\
\hline $\begin{array}{l}\text { Forecast } \\
\text { Horizon }\end{array}$ & $\begin{array}{c}\text { Forecast St. } \\
\text { Error } \\
\end{array}$ & VRER & VCPI & VLMI & VINT \\
\hline 1 & 0.000006 & 2.328 & 97.672 & 0.000 & 0.000 \\
\hline 6 & 0.000015 & 1.430 & 98.468 & 0.051 & 0.050 \\
\hline 12 & 0.000018 & 1.077 & 98.783 & 0.037 & 0.102 \\
\hline 18 & 0.000019 & 0.967 & 98.854 & 0.056 & 0.124 \\
\hline \multicolumn{6}{|c|}{ Variance Decomposition (Percentage points) of VLMI } \\
\hline $\begin{array}{l}\text { Forecast } \\
\text { Horizon }\end{array}$ & $\begin{array}{c}\text { Forecast St. } \\
\text { Error } \\
\end{array}$ & VRER & VCPI & VLMI & VINT \\
\hline 1 & 0.00033 & 0.840 & 1.271 & 97.889 & 0 \\
\hline 6 & 0.00080 & 1.002 & 0.359 & 98.460 & 0.179 \\
\hline 12 & 0.00109 & 1.044 & 0.612 & 98.055 & 0.289 \\
\hline 18 & 0.00129 & 1.019 & 1.424 & 97.213 & 0.344 \\
\hline \multicolumn{6}{|c|}{ Variance Decomposition (Percentage points) of VINT } \\
\hline $\begin{array}{l}\text { Forecast } \\
\text { Horizon }\end{array}$ & $\begin{array}{c}\text { Forecast St. } \\
\text { Error } \\
\end{array}$ & VRER & VCPI & VLMI & VINT \\
\hline 1 & 3.158 & 0.398 & 0.055 & 0.005 & 99.541 \\
\hline 6 & 3.476 & 7.097 & 0.776 & 1.207 & 90.920 \\
\hline 12 & 3.492 & 7.038 & 1.309 & 1.505 & 90.149 \\
\hline 18 & 3.503 & 6.995 & 1.635 & 1.765 & 89.604 \\
\hline
\end{tabular}

Finally, in the last two columns, we reported the effects of VLMI and VINT on the said macroeconomic series. One can observe from the figure that initially, the response of VRER, VCPI, and VINT to one standard deviation shock to VLMI 
is positive and significant. However, this response immediately fades away. On the other hand, the response of VLMI to its own shock seems persistent overtime. Similarly, the response of VRER to VINT is positive and it remains positive up to a time horizon of 8 months. Overall, the impulse response function provides strange evidence on the significant response of the underlying volatility series to not only their own shocks but also shocks to the other volatility series.

\section{Conclusion and Policy Recommendations}

The main contribution of this paper is to provide empirical evidence on the interlinkages between four types of macroeconomic volatilities for the period of January 1988 to December 2017. For this purpose, the paper applies the Granger causality test in a multivariate framework, and variance decomposition. IRFs are also estimated in order to confirm the interactions between the underlying macroeconomic volatility series. The results of the multivariate Granger causality test indicate that there is bidirectional Granger causality between VRER and VLMI. Similarly, there are also cause-feedback effects between VRER and VINT. These findings demonstrate that the unexpected variations in VRER, VINT, and VLMI are highly interlinked in Granger sense. Moreover, this piece of evidence also advocates that VRER can be controlled by controlling unexpected variations in both domestic interest rates and output. This result also unveils that the heightened VLMI and VINT not only result in the increased VRER but also are significantly increased by the rise in VRER. The finding indicates that there is a unidirectional causality running from VCPI to VRER, suggesting that controlling the volatility of consumer prices helps in stabilizing VRER. In addition, the empirical findings also exhibit that VRER, VCPI, and VLMI all three simultaneously Granger cause VINT. In a developing country like Pakistan, policymakers often face a problem of higher exchange rate volatility. During the recent past, Pakistan has faced severe VRER. An increase in VRER affects almost all economic agents. Such as traders, exporters, investors, individuals, and business firms, etc. VRER also affects the decisions of the policymakers. The study results are showing robust to any structural break in the data.

Multivariate Granger causality tests suggest that VCPI, VLMI, and VINT simultaneously as well as individually Granger cause VRER. Therefore, from a policy point of view, the government should control VCPI, VLMI, and VINT to minimize VRER because it is relatively easy to lesson VCPI, VLMI, and VINT than VRER. Lower VRER is essential for consistent economic policies. 
Figure 5: Impulse Responses of VRER, VCPI, VLMI and VINT

Response to Cholesky One S.D. (d.f. adjusted) Innov ations \pm 2 S.E.
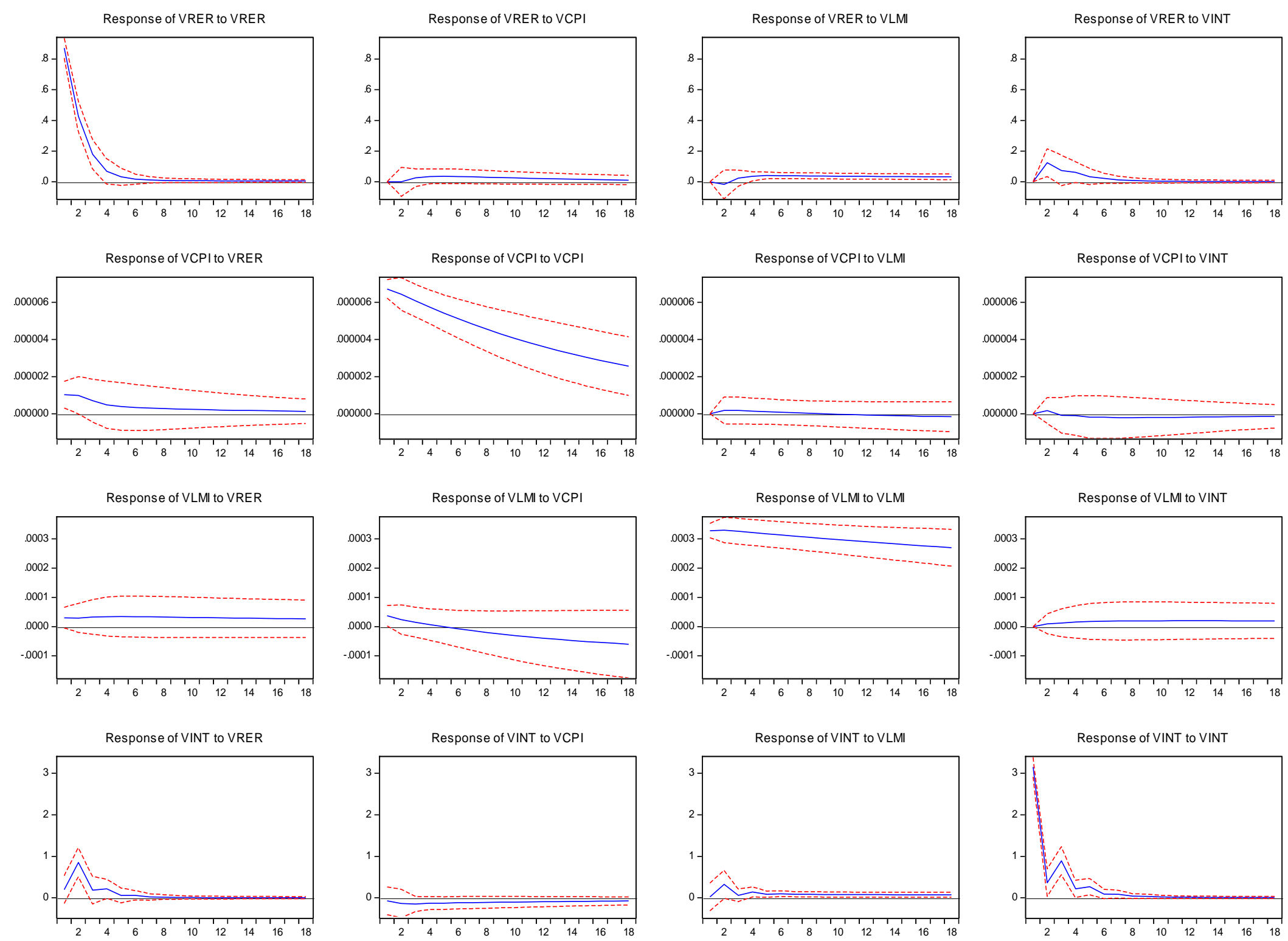
Further, lower VRER not only helpful for policymakers to achieve macroeconomic objectives but also important for achieving the external balances by attracting more foreign capital inflows and by motivating domestic and multinational firms to enhance their international trade activities.

This paper can further, be extended by considering other types of macroeconomic volatilities such as unemployment, consumption, and stock price volatilities. One can also extend the analysis of this study by taking into account the moderating and mediating role of one type of uncertainty in establishing the linkage between the other two types of volatilities. Such type of examination will definitely deepen our understanding of the interconnections between the macroeconomic volatilities. 


\section{References}

Abdalla, I. S., \& Murinde, V. (1997). Exchange rate and stock price interactions in emerging financial markets: evidence on India, Korea, Pakistan, and the Philippines. Applied Financial Economics, 7(1), 25-35.

Acemoglu, D., Johnson, S., Robinson, J., \& Thaicharoen, Y. (2003). Institutional causes, macroeconomic symptoms: Volatility, crises, and growth. Journal of Monetary Economics, 50(1), 49-123.

Ajayi, R. A., Friedman, J., \& Mehdian, S. M. (1998). On the relationship between stock returns and exchange rates: Tests of Granger causality. Global Finance Journal, 9(2), 241-251.

Ali, T. M., Mahmood, M. T., \& Bashir, T. (2015). Impact of interest rate, inflation and money supply on exchange rate volatility in Pakistan. World Applied Sciences Journal, 33(4), 620-630.

Barguellil, A., Ben-Salha, O., \& Zmami, M. (2018). Exchange rate volatility and economic growth. Journal of Economic Integration, 33(2), 1302-1336.

Barrot, L. D., Calderón, C., \& Servén, L. (2018). Openness, specialization, and the external vulnerability of developing countries. Journal of Development Economics, 134(1), 310-328.

Berument, H., \& Pasaogullari, M. (2003). Effects of the real exchange rate on output and inflation: Evidence from Turkey. The Developing Economies, 41(4), 401-435.

Bloom, N. (2014). Fluctuations in uncertainty. The Journal of Economic Perspectives, 28(2), 153-175.

Bollerslev, T. (1986). Generalized autoregressive conditional heteroskedasticity. Journal of Econometrics, 31(3), 307-327.

Comin, D., \& Mulani, S. (2006). Diverging trends in aggregate and firm volatility. The Review of Economics and Statistics, 88(2), 374-383.

Comin, D., \& Philippon, T. (2005). The rise in firm-level volatility: Causes and consequences. NBER Macroeconomics Annual, 20(1), 167-201.

Elder, J., \& Kennedy, P. E. (2001). Testing for unit roots: what should students be taught?. The Journal of Economic Education, 32(2), 137-146. 
Engle, R. F. (1982). Autoregressive conditional heteroscedasticity with estimates of the variance of United Kingdom inflation. Econometrica, 50(4), 9871008 .

Granger, C. W. (1969). Investigating causal relations by econometric models and cross-spectral methods. Econometrica,37(3), 424-438.

Hölzl, W., \& Huber, P. (2009). An anatomy of firm level job creation rates over the business cycle (No. 348). WIFO Working Papers.

Imbs, J. (2007). Growth and volatility. Journal of Monetary Economics, 54(7), 1848-1862.

Islam, T. S., Wadud, M. A., \& Islam, Q. B. T. (2007). Relationship between education and GDP growth: A multivariate causality analysis for Bangladesh. Economics Bulletin, 3(35), 1-7.

Jabeen, M., \& Khan, S. A. (2014). Modelling exchange rate volatility by macroeconomic fundamentals in Pakistan. International Econometric Review, 6(2), 58-76.

Jawaid, S. T., \& Ul Haq, A. (2012). Effects of interest rate, exchange rate and their volatilities on stock prices: evidence from banking industry of Pakistan. Theoretical \& Applied Economics, 19(8) 153-166.

Johansen, S., \& Juselius, K. (2017). Direct and spill-over effects of exchange rate volatility on inflation in Swaziland: An Application of the Multivariate GARCH Model. Research Bulletin Volume, 52(2), 84-107.

Kholdy, S., \& Sohrabian, A. (1990). Exchange rates and prices: evidence from Granger causality tests. Journal of Post Keynesian Economics, 13(1), 7178.

Knight, F. H. (1921). Risk, uncertainty and profit. New York: Hart, Schaffner and Marx.

Khin, A. A., Yee, C. Y., Seng, L. S., Wan, C. M., \& Xian, G. Q. (2017). Exchange rate volatility on macroeconomic determinants in Malaysia: Vector error correction method (VECM) model. Journal of Global Business and Social Entrepreneurship (GBSE) 3(5), 36-45.

Ladokhin, S. (2009). Volatility modeling in financial markets. A Master Thesis. VU University, Amsterdam. 
Loayza, N. V., Ranciere, R., Servén, L., \& Ventura, J. (2007). Macroeconomic volatility and welfare in developing countries: An introduction. The World Bank Economic Review, 21(3), 343-357.

Loayza, N., \& Hnatkovska, V. V. (2004). Volatility and growth. World Bank Policy Research Working Paper, (3184).

Morana, C. (2009). On the macroeconomic causes of exchange rate volatility. International Journal of Forecasting, 25(2), 328-350.

Muhammad, N., Rasheed, A., \& Husain, F. (2002). Stock prices and exchange rates: Are they related? evidence from south asian countries [with comments]. The Pakistan Development Review, 535-550.

Pham, T. A. (2018). Policy volatility and growth. Portuguese Economic Journal, 17(2), 87-97.

Ramey, G., \& Ramey, A. (1995). Cross-country evidence on the link between volatility and growth. The American Economic Review, 85(5), 1138-1151.

Rashid, A. (2008). Macroeconomic variables and stock market performance: Testing for dynamic linkages with a known structural break. Savings and Development, 32(1), 77-102.

Rehman, I. U., \& Aftab, M. (2015). On the linkages between exchange rate, inflation and interest rate in Malaysia: Evidence from autoregressive distributed lag modeling. Pakistan Journal of Statistics, 31(5), 609-622.

Sarantis, N. (1999). Modeling non-linearities in real effective exchange rates. Journal of International Money and Finance, 18(1), 27-45.

Stock, J. H., \& Watson, M. W. (2012). Disentangling the Channels of the 20072009 Recession (No. w18094). National Bureau of Economic Research.

Türsoy, T. (2017). Causality between stock prices and exchange rates in Turkey: Empirical evidence from the ARDL bounds test and a combined cointegration approach. International Journal of Financial Studies, 5(1), $1-10$.

De Veirman, E., \& Levin, A. (2018). Cyclical changes in firm volatility. Journal of Money, Credit and Banking, 50(2-3), 317-349. 


\section{Annexure 1}

Table 1: Granger Causality Test Results (structural break atomic tests 28 May, 1998)

\begin{tabular}{|c|c|c|}
\hline \multicolumn{3}{|c|}{ Dependent Variable: VRER } \\
\hline Excluded & Chi-sq & Prob. \\
\hline VCPI & 27.055 & 0.019 \\
\hline VLMI & 51.468 & 0.000 \\
\hline VINT & 32.392 & 0.004 \\
\hline All & 136.705 & 0.000 \\
\hline \multicolumn{3}{|c|}{ Dependent Variable: VCPI } \\
\hline Excluded & Chi-sq & Prob. \\
\hline VRER & 15.481 & 0.346 \\
\hline VLMI & 30.252 & 0.007 \\
\hline VINT & 7.023 & 0.934 \\
\hline All & 50.587 & 0.679 \\
\hline \multicolumn{3}{|c|}{ Dependent Variable: VLMI } \\
\hline Excluded & Chi-sq & Prob. \\
\hline VRER & 21.166 & 0.098 \\
\hline VCPI & 15.553 & 0.341 \\
\hline VINT & 36.008 & 0.001 \\
\hline All & 107.832 & 0.000 \\
\hline \multicolumn{3}{|c|}{ Dependent Variable: VINT } \\
\hline Excluded & Chi-sq & Prob. \\
\hline VRER & 24.133 & 0.044 \\
\hline VCPI & 18.248 & 0.196 \\
\hline VLMI & 19.206 & 0.157 \\
\hline All & 142.991 & 0.000 \\
\hline
\end{tabular}




\section{Annexure 2}

Table 2: Granger Causality Test Results (structural break 9/11)

\begin{tabular}{|c|c|c|}
\hline \multicolumn{3}{|c|}{ Dependent Variable: VRER } \\
\hline Excluded & Chi-sq & Prob. \\
\hline VCPI & 25.686 & 0.019 \\
\hline VLMI & 33.134 & 0.002 \\
\hline VINT & 24.247 & 0.029 \\
\hline All & 97.653 & 0.000 \\
\hline \multicolumn{3}{|c|}{ Dependent Variable: VCPI } \\
\hline Excluded & Chi-sq & Prob. \\
\hline VRER & 17.056 & 0.197 \\
\hline VLMI & 26.675 & 0.014 \\
\hline VINT & 6.766 & 0.914 \\
\hline All & 52.597 & 0.451 \\
\hline \multicolumn{3}{|c|}{ Dependent Variable: VLMI } \\
\hline Excluded & Chi-sq & Prob. \\
\hline VRER & 23.811 & 0.033 \\
\hline VCPI & 10.950 & 0.615 \\
\hline VINT & 33.896 & 0.001 \\
\hline All & 79.420 & 0.009 \\
\hline \multicolumn{3}{|c|}{ Dependent Variable: VINT } \\
\hline Excluded & Chi-sq & Prob. \\
\hline VRER & 28.011 & 0.009 \\
\hline VCPI & 11.913 & 0.535 \\
\hline VLMI & 13.103 & 0.439 \\
\hline All & 62.828 & 0.145 \\
\hline
\end{tabular}

